\title{
TRANSNATIONAL CORPORATIONS AS BUSINESS ENTITIES IN THE BANKING SECTOR
}

\author{
Tatyana V. Kokoreva \\ LLC "Kontsessii teplosnabzheniya", Volgograd, Russian Federation
}

\begin{abstract}
Introduction: the paper is devoted to the study of the essence of understanding TNCs in the banking sector through the analysis of such concepts as "transnational company (corporation)", "international company (corporation)", "international bank" and "transnational bank". To this end, the author examines the concept and features of transnational corporations in the banking sector, their essential features, highlighted by the civil doctrine and used by judicial practice. Using the methods of scientific cognition, primarily the method of system and comparative analysis, the author identifies the constituent features of a transnational corporation by applying an insight-substantive approach to the study of the concept of TNCs as the largest intermediary in the system of international capital migration. Results: it is established that in the modern scientific literature there is no single approach to understanding the transnational corporation in the banking sector. In order to determine the main approaches to the understanding of TNCs in the banking sector, the author's approaches to the definition of this phenomenon are systematized. The study identifies three groups of approaches: a TNC as a national company transcending the state; a TNC as a set of national companies; a TNC as a parent company operating in several states. Conclusions: the author concludes that a TNC in the banking sector should be understood as a transnational bank operating in several countries on the basis of an institutionalized network of representative offices operating on the basis of the national legislation of the countries of operation, which allows them to ensure the international movement of capital in order to diversify the economy and stimulate the innovative development of international economic relations.
\end{abstract}

Key words: banking, transnational corporation, multinational banks, national currency, civil transactions, representation system.

Citation. Kokoreva T.V. Transnational Corporations as Business Entities in the Banking Sector. Legal Concept = Pravovaya paradigma, 2020, vol. 19, no. 4, pp. 137-143. (in Russian). DOI: https://doi.org/10.15688/lc.jvolsu.2020.4.18

\section{ТРАНСНАЦИОНАЛЬНЫЕ КОРПОРАЦИИ КАК СУБЪЕКТЫ ХОЗЯЙСТВОВАНИЯ В БАНКОВСКОЙ СФЕРЕ}

\author{
Татьяна Васильевна Кокорева
}

ООО «Концессии теплоснабжения», г. Волгоград, Российская Федерация

Введение: статья посвящена исследованию сущности понимания ТНК в банковской сфере через анализ таких понятий, как «транснациональная компания (корпорация)», «международная компания (корпорация)», «международный банк» и «транснациональный банк». С этой целью автор рассматривает понятие и 을 признаки транснациональных корпораций в банковской сфере, их существенные особенности, выделяемые 워․ цивилистической доктриной и используемые судебной практикой. С помощью методов научного познания, пे прежде всего метода системного и сравнительного анализа, автор выделяет конституирующие признаки транснациональной корпорации путем применения сущностно-субстанционального подхода к изучению ТНК как крупнейшего посредника в системе международной миграции капиталов. Результат корпо (?) сфере проведена систематизация авторских подходов к определению данного явления. В исследовании 
выделены три группы подходов: ТНК как национальная компания, вышедшая за пределы государства; ТНК как совокупность национальных компаний; ТНК как головная компания, присутствующая в нескольких государствах. Выводы: автором сделан вывод о том, что под ТНК в банковской сфере необходимо понимать транснациональный банк, осуществляющий свою деятельность в нескольких странах на основе институализированной сети представительств, действующих на основании национального законодательства стран присутствия, что позволяет им обеспечивать международное движение капиталов в целях диверсификации экономики и стимулировать инновационное развитие международных экономических связей.

Ключевые слова: банковская деятельность, транснациональная корпорация, транснациональные банки, национальная валюта, гражданско-правовые сделки, система представительства.

Цитирование. Кокорева Т. В. Транснациональные корпорации как субъекты хозяйствования в банковской сфере // Legal Concept = Правовая парадигма. - 2020. - T. 19, № 4. - C. 137-143. - DOI: https://doi.org/10.15688/lc.jvolsu.2020.4.18

\section{Введение}

В условиях глобализации рынков возникает необходимость совершенствования системы финансовых отношений и повышения уровня доступности капиталов. На сегодняшний день транснациональные компании (далее - ТНК) в банковской сфере являются крупнейшими посредниками в системе международной миграции капиталов. В современной научной литературе не сложилось единого подхода к пониманию ТНК в банковской сфере, что связано с междисциплинарным характером организации деятельности подобных финансовых институтов. С одной стороны, следует опираться на экономическое содержание их деятельности, с другой - необходимо отразить специфику правового закрепления деятельности данных институтов в конкретных странах и выработать единый системный подход к координации международного правового регулирования их функционирования. Исследование ТНК преимущественно лежит в плоскости экономической науки, в то время как юридическая наука рассматривает отдельные аспекты международно-правового регулирования деятельности ТНК.

\section{Понятие, основные характеристики ТНК в банковской сфере}

Научное закрепление дефиниции «транснациональных компаний» началось после публикации исследования Д. Лилиенталя [12, c. 74] в 1960 году. Помимо термина «транснациональная компания (корпорация)» [10, c. 153] также используются «международная организация», многонациональная [9, с. 420] (мультинациональная [15, с. 60], международная) корпорация (компания, предприятие, монополия).

Трехсторонняя декларация принципов, касающихся многонациональных предприятий социальной политики МОТ [5, с. 19], а также Руководство ОЭСР о многонациональных предприятиях [14] указывают, что национальный состав ТНК не может считаться существенным признаком для ее определения. Напротив, Руководство устанавливает, что приоритетным признаком ТНК является наличие таких хозяйственных связей, которые позволяют нескольким государствам значительно влиять на деятельность других.

Вопрос наименования хозяйствующих субъектов, осуществляющих свою деятельность за пределами одного государства, остается дискуссионным не только в научной литературе, но и в документах международных организаций. При этом возможно выделить ряд существенных особенностей, свойственных данному типу организационных отношений: трансграничный характер деятельности хозяйствующих субъектов; организационное и экономическое единство; интернациональный состав менеджмента организации; монопольная природа корпорации и стремление распространить свое влияние на зарубежных ранках (не менее $25 \%$ от объемов рынка); высокий научно-технический и инновационный уровень производства; национальная принадлежность капитала и акционерной собственности.

В современной научной литературе также нет единого подхода к пониманию такого типа транснациональных корпораций, как ТНК в банковской сфере. Среди исследователей 
T.B. Кокорева. Транснациональные корпорации как субъекты хозяйствования в банковской сфере

наиболее распространенным является использование термина «транснациональный банк» (далее - ТНБ), употребление которого характерно для ученых-экономистов. В то же время в юридической литературе данный термин до настоящего момента не употреблялся.

На сегодняшний день можно выделить несколько основных подходов к пониманию ТНБ, которые описываются в исследованиях по мировой экономике. Так, Ю.В. Макогон определяет данный вид хозяйствующих субъектов как крупнейшие банковские учреждения универсального типа, располагающие широко разветвленной и тесно интегрированной системой зарубежных предприятий, контролирующие мировой финансовый рынок [3, с. 50]. Схожую позицию высказывает Б.А. Райзберг [4, с. 407], который также указывает на посредническую роль ТНБ в международном движении капиталов. В свою очередь П.Р. Кругман [2, с. 714] акцентирует внимание на международном характере деятельности банков и наличии зарубежных активов. Масштаб деятельности ТНБ отражает в своем определении А. Яковлева [8, с. 117], которая называет ТНБ «гигантскими финансовыми империями», определяющими порядок финансовых отношений как внутри стран, так и за их пределами.

Как утверждают Е.А. Шутаева и В.В. Побирченко [7, с. 151], главной характеристикой ТНБ является наличие институализированной сети зарубежных представительств и перенос части своей деятельности за пределы одного государства. В связи с этим ключевым показателем деятельности ТНБ является определение доли активов и пассивов, связанных с международной деятельностью, а также доли прибыли, получаемой от нее.

Таким образом, банковский капитал является национальным по своему происхождению и трансграничным по сфере деятельности, то есть он одновременно входит как подсистема в национальную экономическую систему и выступает элементом мировой экономики. При этом в процессе трансграничного перехода национальный капитал сохраняет национальные особенности распределения и в то же время приобретает характеристики банковского капитала страны, в которой он ис- пользуется. Данное положение определяет деятельность ТНК в банковской сфере.

Транснационализация банковских отношений предполагает реализацию нескольких направлений сотрудничества государств. В частности, определение порядка построения долгосрочных инвестиционных связей с промышленными предприятиями в странах-реципиентах капитала, порядка передачи информации, технологий и опыта проведения банковских операций.

При этом особенностью современных транснациональных банковских компаний является быстрое развитие мирового финансового рынка, на котором крайне сложно выделить исключительно национальный капитал. В силу того факта, что акции крупных ТНБ продаются на международной фондовой бирже, их владельцами в разных долях являются представители нескольких стран, что делает невозможным определение национальной принадлежности того или иного ТНБ. В данном случае мировая практика определяет принадлежность капитала по стране, в которой концентрируется контрольный пакет акций банка, что несколько упрощает порядок регламентации деятельности ТНК в банковской сфере.

Органический рост ТНК в банковской сфере позволяет снизить риски, связанные с переводом капитала в зарубежные страны. Данный процесс требует большего времени, но при этом он позволяет увеличить объем представительства с учетом нормативно-правового регулирования в странах-реципиентах. Однако в ряде стран присутствуют законодательные ограничения, которые не позволяют иностранным банкам увеличить долю своего присутствия в национальном капитале. Установление законодательных ограничений на расширение ТНБ в отдельных странах часто связаны с несовершенством национальной банковской системы, что требует от правительств проведения политики протекционизма.

Анализ особенностей ТНК в банковской сфере позволил выделить ряд ключевых характеристик данного вида хозяйствующих субъектов:

1) ТНК в банковской сфере представляет собой крупную банковскую монополию, способную воздействовать не только на на- 
циональный, но и международный рынок финансовых инструментов;

2) деятельность ТНК в банковской сфере носит глобальный характер;

3) в структуре их деятельности значительный объем занимают международные операции;

4) высокая степень защиты банковских операций позволяет привлечь более надежных клиентов по всему миру.

Под ТНК в банковской сфере предлагается понимать транснациональный банк, осуществляющий свою деятельность в нескольких странах на основе институализированной сети представительств, действующих на основании национального законодательства стран присутствия, что позволяет им обеспечивать международное движение капиталов в целях диверсификации экономики и стимулировать инновационное развитие [11, с. 240] международных экономических связей.

\section{Виды и классификация ТНК в банковской сфере}

В силу того факта, что ТНК в банковской сфере не выступают самостоятельным объектом изучения, в научной литературе не сложилось методики классификации данных хозяйствующих субъектов. В связи с этим представляется необходимым оценить порядок выделения отдельных видов на основе сложившихся подходов к классификации и систематизации видов транснациональных компаний с учетом определения специфических аспектов для банковской сферы.

В научной литературе в качестве оснований для классификации транснациональных компаний принято выделять цели, стратегии развития, организационную структуру и способы развития инвестиционной деятельности. Вне зависимости от того, какое основание для классификации выделяется, приведенные типологии не могут отразить всей сущности и специфики деятельности ТНК как субъекта правового регулирования в рамках международного частного права.

В качестве первого основания для классификации ТНК большинством ученых выделяется наличие иностранного сектора у компании. В данной классификации выделяют национальные компании, которые не имеют своих представительств в других странах, и ТНК. В свою очередь последние разделяются на интернациональные, многонациональные и глобальные. Различия между данными формами определяются системой менеджмента и организации транснационального взаимодействия.

Многонациональные корпорации - корпорации, объединяющие юридически независимые национальные банки нескольких государств на организационной основе, связывая их финансово-экономическими инструментами.

По характеру интеграции в работе S.X. Liu [13, с. 49] ТНК разделены на вертикально интегрированные и горизонтально интегрированные. Вертикально интегрированные ТНК в банковской сфере устроены по принципу формирования соответствующих связей между поставщиками финансовых продуктов и их потребителями. Возникает иерархичная структура, что позволяет снизить издержки, связанные с несогласованностью в действиях контрагентов.

Горизонтально интегрированные ТНК в банковской сфере направлены прежде всего на обеспечение защиты информации, необходимой для осуществления их деятельности, что обеспечивает конкурентные преимущества на инвестиционном и кредитном рынках.

При анализе форм коммерческой деятельности ТНК выделяются такие как холдинг, ассоциация, консорциум, картель, трест, пул, синдикат, концерн и финансово-промышленная группа [6, с. 11]. Однако применительно к банковской сфере мы можем выделить только отдельные из указанных форм.

Например, одной из форм ТНК в банковской сфере являются банковские ассоциации, под которыми понимается структура, объединяющая коммерческие банки с целью защиты профессиональных интересов.

В банковской сфере принято выделять также банковский консорциум или синдикат это объединение банков, с целью проведений совместных финансовых операций. Главой консорциума выступает одна из наиболее крупных банковских организаций. Цели, которые преследуются при создании синдиката: расширение сфер деятельности и выход на новый рыночный уровень, проведение совме- 
T.B. Кокорева. Транснациональные корпорации как субъекты хозяйствования в банковской сфере

стных кредитных и других видов финансовых операций.

Наиболее крупными формами ТНК в банковской сфере являются банковские картели - это соглашение между крупнейшими банками о разделе сфер деятельности, которое предполагает сохранение самостоятельности каждого из участников данной структуры.

Финансово-промышленная группа (далее - ФПГ) в свою структуру, как правило, включает финансовую организацию. В связи с этим нецелесообразно рассматривать его как самостоятельную форму ТНК в банковской сфере. Кроме того, в контексте развития ФПГ банковский сектор выступает как вспомогательный элемент усиления ТНК.

По мнению Е.А. Королева, подобная классификация отражает общие тенденции развития мировой экономики и процесса глобализации. Следовательно, формы существования ТНК следует рассматривать исключительно как начальные позиции международного сотрудничества [1, с. 79].

По причинам осуществления деятельности выделяют два вида ТНК: ищущие факторы производства и расширяющие рынок. Первая группа ТНК в банковской сфере стремится увеличить денежную массу банка за счет аккумулирования средств резидентов из других стран. В свою очередь ТНК, расширяющие рынок, напротив, ориентированы на потребителей кредитных и инвестиционных продуктов. Такие ТНК ориентированы на построение горизонтальных связей.

По профессиональной направленности выделяют производственные ТНК (в банковской сфере такие ТНК создают новые продукты и формы взаимодействия) и сервисные (в банковской сфере обслуживают уже сложившиеся финансовые связи и продукты).

По организационному построению деятельность ТНК в банковской сфере основывается на тех стратегических направлениях, которые характерны для материнского (головного) банка. В связи с этим предпринять попытку классификации ТНК в банковской сфере по признаку стратегии или связанной с ней организационной структурой не представляется возможным, так как они представляют собой динамическую систему.

\section{Выводы}

Таким образом, анализ существующих в научной литературе подходов к классификации транснациональных компаний в банковской сфере позволил выявить существующую необходимость выделения данного вида хозяйствующих субъектов в самостоятельную область исследования. Применительно к ТНК в банковской сфере представляется возможным использовать отдельные типологии, к которым прежде всего следует отнести классификацию по формам. Последняя позволяет отразить типы связей между головным (материнским) банком и представительствами за рубежом. Кроме того, определение формы ТНК в банковской сфере предопределяет применение и других типологий, в первую очередь по организационной структуре.

Однако ни одна из указанных классификаций не позволяет раскрыть особенности правового регулирования деятельности ТНК в банковской сфере. По данному признаку предлагается разделять ТНК три категории:

1. Осуществляющие свою деятельность на основании международно-правовых нормативно-правовых актов (данная категория наиболее общая и представляет собой международные банки, в которых участвуют большинство стран. Ключевой задачей таких банков является поддержание соответствующего уровня развития мировой экономики, а также выработка единой концепции развития банковского сектора международной экономики).

2. Осуществляющие свою деятельность в соответствии с нормативно-правовыми актами головного (материнского) банка (данная категория активно создает свои представительства в развивающихся странах, одновременно стимулируя развитие национальных экономик и формирование национальной банковской системы).

3. Осуществляющие свою деятельность в соответствии с требованиями правовой системы страны пребывания (данная категория функционирует в развитых странах и формирует свои продукты, а также систему менеджмента таким способом, который позволяет максимально быстро и эффективно оптимизировать их под особенности правового регулирования разных стран). 
Таким образом, нормативное регулирование деятельности ТНК в банковской сфере предполагает анализ норм международного права, регулирующих банковскую деятельность и наиболее распространенных норм, используемых в национальных системах для обеспечения одновременно безопасности банковских операций и защиты национальной экономики от экспансии со стороны иностранных государств.

\section{СПИСОК ЛИТЕРАТУРЫ}

1. Королев, А. Е. Транснациональные корпорации как субъекты международного частного права : дис. ... канд. юрид. наук : 12.00 .03 / Королев Александр Евгеньевич. - Саратов, 2001.- 223 с.

2. Кругман, П. Р. Международная экономика / П. Р. Кругман, М. Обстфельд. - 5-е изд. - СПб. : Питер, 2004. -832 c.

3. Матыцин, Д. Е. Сделки на рынке ценных бумаг: цифровые технологии защиты прав и законных интересов инвесторов : монография / Д. Е. Матыцин. - Волгоград : Изд-во ВолГУ, 2019. - 187 с.

4. Райзберг, Б. А. Современный экономический словарь / Б. А. Райзберг, П. Ш. Лозовский. - М. : ИНФРА-М, 2003. - $476 \mathrm{c}$.

5. Трехсторонняя декларация принципов, касающихся многонациональных корпораций и социальной политики. - Женева : Международное бюро труда, 2001. - 30 c.

6. Уткин, Э. А. Финансово-промышленные группы : дис. ... канд. экон. наук : 11.00.07 / Уткин Эдуард Андреевич. - М. : Юрист, 1997. - С. 10-18.

7. Шутаева, Е. А. Транснациональные банки в условиях финансовой глобализации / Е. А. Шугаева, В. В. Побирченко // Ученые записки Таврического национального университета имени В.И. Вернадского. Экономика и управление. - 2009. - Т. 1, № 22 (61). - C. 149-164.

8. Яковлева, А. А. Транснациональные банки и финансовые институты: сущность и стратегии развития / А. А. Яковлева // Вопросы экономики. 2006. - № 10. - C. 114-123.

9. Abdulsomad, K. The Transformation of Multinational Corporations (MNCs) from an Innovation Perspective: Some Notes on the Theories of MNCs / K. Abdulsomad // AI and Society. - 2014. Vol. 29, iss. 3. - P. 415-426.

10. Inshakova, A. O. TNCs as Subjects of Economic Activity and Lawmaking in the Sphere of Foreign Trade in Energy Resources / A. O. Inshakova, E. E. Frolova, I. P. Marchukov // Lecture Notes in Networks and Systems. - 2019. - Vol. 44. - P. 151-171.
11. Inshakova, E. I. Neo-Industrialization of the Russian Economy: Technological and Digital Development. Ubiquitous Computing and the Internet of Things: Prerequisites for the Development of ICT / E. I. Inshakova, A. Y. Ryzhenkov, A. O. Inshakova // Studies in Computational Intelligence / ed. by E. G. Popkova. - Cham : Springer Science + Business Media. - 2019. - Vol. 826. - P. 239-250.

12. Lilienthal, D. The Multinational Corporation / D. Lilienthal // Management and Corporations/ed. by M. Anshen, G. L. Bash. - N. Y. : Greenwood , 1985.P. 74-82.

13. Liu, S. X. Foreign Direct Investment and Multinational Enterprises / S. X. Liu. - N. Y. : Praeger, 1997. $-178 \mathrm{p}$.

14. OECD Guidelines for Multinational Enterprises. - Electronic text data. - Mode of access: http://www.oecd.org/daf/investment/guidelines (date of access: 16.11.2020). - Title from screen.

15. Perrot, F. Multinational Corporations' Strategies at the Base of the Pyramid: An Action Research Inquiry / F. Perrot // Journal of Business Ethics. - 2017. - Vol. 146, iss. 1. - P. 59-76.

\section{REFERENCES}

1. Korolev A.E. Transnatsionalnye korporatsii kak subyekty mezhdunarodnogo chastnogo prava: dis ... kand. jurid. nauk: 12.00.03 [Transnational Corporations as Subjects of Private International Law: Dis. ... Cand. the Faculty of Law Sciences: 12.00.03]. Saratov, 2001. $223 \mathrm{p}$.

2. Krugman P.R., Obstfeld M. Mezhdunarodnaya ekonomika [International Economics]. Saint Petersburg, Piter Publ., 2004. 832 p.

3. Matytsin D.E. Sdelki na rynke tsennykh bumag: tsifrovye tekhnologii zashchity prav $i$ zakonnykh interesov investorov: monografiya [Transactions in the Securities Market: Digital Technologies for Protecting Rights and Legitimate Interests of Investors. Monograph]. Volgograd, Izd-vo VolGU, 2019. 187 p.

4. Raizberg B.A., Lozovsky P.S. Sovremennyy ekonomicheskiy slovar [Modern Economic Dictionary]. Moscow, INFRA-M Publ., 2003. 476 p.

5. Trekhstoronnyaya deklaratsiya printsipov, kasayushchikhsya mnogonatsionalnykh korporatsiy i sotsialnoy politiki [Trilateral Declaration of Principles Concerning Multinational Corporations and Social Policy]. Geneva, International Labour Office, 2001.30 p.

6. Utkin E.A. Finansovo-promyshlennye gruppy: dis. ... kand. ekon. nauk: 11.00.07[Financial and Industrial Groups: dis. ... Candidate of Economics Sciences: 11.00.07]. Moscow, Yurist Publ., 1997, pp. 10-18.

7. Shutaeva E.A., Pobirchenko V.V. Transnatsionalnye banki $\mathrm{v}$ usloviyakh finansovoy globalizatsii [Transnational Banks in the Conditions 
T.B. Кокорева. Транснациональные корпорации как субъекты хозяйствования в банковской сфере

of Financial Globalization]. Uchenye zapiski Tavricheskogo natsionalnogo universiteta imeni V.I. Vernadskogo. Ekonomika i upravlenie [Scientific notes of the Tauride national University named after V. I. Vernadsky. Economy and management], 2009, vol. 1, no. 22 (61), pp. 149-164.

8. Yakovleva A.A. Transnatsionalnye banki i finansovye instituty [Transnational Banks and Financial Institutions: Essence and Development Strategies]. Voprosy ekonomiki [Economic Issues], 2006, no. 10, pp. 114-123.

9. Abdulsomad K. The Transformation of Multinational Corporations (MNCs) from an Innovation Perspective: Some Notes on the Theories of MNCs. AI and Society, 2014, vol. 29, iss. 3, pp. 415-426.

10. Inshakova A.O., Frolova E.E., Marchukov I.P. TNCs as Subjects of Economic Activity and Lawmaking in the Sphere of Foreign Trade in Energy Resources. Lecture Notes in Networks and Systems, 2019, vol. 44, pp. 151-171.
11. Inshakova E.I., Ryzhenkov A.Y., Inshakova A.O. Neo-Industrialization of the Russian Economy: Technological and Digital Development. Ubiquitous Computing and the Internet of Things: Prerequisites for the Development of ICT. Studies in Computational Intelligence. Cham, Springer Science + Business Media, 2019, vol. 826, pp. 239-250.

12. Lilienthal D. The Multinational Corporation. Management and Corporations. Anshen M., Bash G. L., eds. New York, Greenwood, 1985, pp. 74-82.

13. Liu S.X. Foreign Direct Investment and Multinational Enterprises. New York, Praeger, 1997, pp. 49-50.

14. OECD Guidelines for Multinational Enterprises. URL: http://www.oecd.org/daf/investment/ guidelines (accessed 16 November 2020).

15. Perrot F. Multinational Corporations' Strategies at the Base of the Pyramid: An Action Research Inquiry. Journal of Business Ethics, 2017, vol. 146, iss. 1, pp. 59-76.

\section{Information About the Author}

Tatyana V. Kokoreva, Head of the Department for Coordination with the Law Enforcement Unit and Official Investigations, LLC "Kontsessii teplosnabzheniya", Port-Saida St, 16A, 400066 Volgograd, Russian Federation, info@teplovolgograd.ru, https://orcid.org/0000-0002-2159-0682

\section{Информация об авторе}

Татьяна Васильевна Кокорева, руководитель управления по взаимодействию с правоохранительным блоком и проведения служебных расследований, ООО «Концессии теплоснабжения», ул. Порт-Саида, 16А, 400066 г. Волгоград, Российская Федерация, info@teplovolgograd.ru, https://orcid.org/0000-0002-2159-0682 